\title{
The vision of transformation in medical education after the COVID-19 pandemic
}

Poh Sun Goh

Yong Loo Lin School of Medicine, National University of Singapore, Singapore

This commentary is based on, and extends upon, a keynote presentation given at the Korean Society of Medical Education 2021 conference on June 3, 2021. The presentation slides and a separate full transcript of a narrated complementary presentation, as well as the cited reference material, are available on a customized blog, shared with conference participants 1 week before the presentation. Half the allocated session time was utilized for a live question and answer section, which is expanded upon within a separate section within the session blog. In anticipation of elaboration of my presentation during the later part of the allocated session time, I wrote a series of short paragraphs articulating key narrative threads related to the topic, and these were posted on the session blog [1]. I have curated these paragraphs scattered throughout the blog, and rearranged them to form a coherent linear narrative in this commentary.

The ongoing coronavirus disease 2019 (COVID-19) pandemic is currently gripping the world, literally on a global scale, affecting lives and livelihoods. It is clear that we will be living 'with' COVID-19, in the near future, for at least several years, in a dynamic interaction between our adaptability and resilience as a human race, and that of the COVID-19 virus. The COVID-19 pandemic is a "stress-test" of profound magnitude, and is potentially only the prelude to greater challenges we will face in the coming years and decades, in the first half of the 21st century. In the presentation, reference was made to the past, present, and (possible) future; what we can and arguably should keep, what we can (and arguably could) discard or change, and what we could imagine, and envision ourselves doing, to transform medical education [1-3]. This was placed in a broader context of the nature of work [4], technology trends of the present $[5,6]$, and a history of medical education $[7,8]$.

As a scenario building and discussion exercise, we could consider three potential futures: (1) firstly, a continuation of current practice in medical education, with "emergency eLearning" or use of technology, blended with in-person activities, with ongoing exploration of "newer technologies" like tele-health, virtual
Received: July 29, 2021 • Revised: August 6, 2021 • Accepted: August 9, 2021 Corresponding Author: Poh Sun Goh (https://orcid.org/0000-0002-1531-2053)

Yong Loo Lin School of Medicine, National University Hospital, National University of Singapore, Main Building, Level 3, 5 Lower Kent Ridge Road, Singapore Tel: +065.6779.5555 Fax: +65.6773.0190 email: dnrgohps@nus.edu.sg
Korean J Med Educ 2021 Sep; 33(3): 171-174

https://doi.org/10.3946/kjme.2021.197

eISSN: 2005-7288

(C) The Korean Society of Medical Education. All rights reserved. This is an open-access article distributed under the terms of the Creative Commons Attribution Non-Commercial License (http:// creativecommons.org/licenses/by-nc/3.0/), which permits unrestricted non-commercial use, distribution, and reproduction in any medium, provided the original work is properly cited. 
and augmented reality (VR and AR) and mixed reality (MR), and use of artificial intelligence (AI) and robotics; (2) secondly, in addition to the first scenario practice, wide-spread, global multi-site, no-cost or low-cost rapid prototyping innovation including experimenting with disruptive paradigms, global co-operative sharing and co-developing of open access digital content, and simulation paradigms, which are shared globally, at no-cost; including having the very best teachers and instructors design, build and curate (with attribution) the very best content; localized and customized by a combination of $\mathrm{AI}$ and well trained, passionate local educators, with digital literacy and life-long learning skills and competencies part of the core curriculum for all current and future health professional practitioners; and (3) lastly, consider the first scenario combined with centers of excellence, innovation and disruptive thinking and development, who then propagate best practices and ideas globally, funded by public-private not-for-profit governance structures, allowing donations and crowdfunding, and tax-free status to resource up this scenario. All three scenarios would be anchored by the best principles and fundamentals of what we know from learning science, innovation and design thinking, and management and leadership best practices -addressing the needs of "hungry students, trained teachers, using what is available and at hand".

Of the three scenarios proposed, it is likely that a combination of "all" three scenarios will play out in medical education, and professional training-lifelong learning settings. This is due to the spectrum of different local practice and individual needs (and motivation), requirements, resource levels, and readiness. There will be innovators, early and late adopters. What is clear, is that technological and digital adoption and transformation is inevitable, and part of our current reality, where-ever one might live, learn, work or practice in.
Arguably, the impact of digital and human tinkering at the edges, and incremental improvement, with step-wise environmental including digital transformative events and tipping points (by chance, or design), will be, hopefully, a general raising of midpoints and the mean of healthcare practice and training outcomes; raising overall standards of practice, doing more with less, while maintaining a spectrum of performance levels, above an acceptable minimal threshold.

May I leave you with one personal insight, and deep conviction that we (humans) will succeed, and thrive, in this era of technological transformation, accelerated worldwide by the COVID-19 pandemic, not only through learning about, and wisely designing-adopting-blending technology tools and platforms, as well as digital content and processes into our day to day lives and work; but by doubling down on, and developing deep insight and expertise into human capabilities and skills. By focusing not only on "artificial intelligence" or AI; but by deliberate, determined efforts "augmenting" our "human" intelligence, by learning how to learn in the most efficient and effective ways possible (through application of learning science), and developing to the "highest" levels our abilities to empathize, communicate, and work together; our interpersonal, intercultural, and working together with each other and understanding each other communication, and dynamic emotional regulation and literacy skills. Blending this with a deep understanding of how human networks, both strong and weak ties, work and function best. Augmented and scaled up by technology tools and platforms.

This presentation has been from the perspective of a clinician-educator, and academic. The viewpoint of an educational administrator and leader, the head of a medical school or a university, and a minister (education, health, finance) would add further insights and perspectives to this discussion, including that of budgets, 
costs (savings, expenditures), manpower (including hiring, training, time allocation, tenure), and accountability (to constituents, the electorate, the public). Not to mention arguably the key stakeholder, the student, the trainee, and the life-long learner. As a thought experiment, please switch roles to that of a student, trainee or life-long learner, engaged in formal or informal learning. What resources do you habitually and routinely access? Those recommended, or do you actively search for additional, more helpful, relevant, and useful material? How do you do this? Where do you do this? Do you have formal training in how to do this? What is the "job to be done"? (to paraphrase Christensen et al. [9] from Harvard Business School). What is "at hand"? -usable, useful, affordable, effective, and efficient (to get the job done). Do you, or would you search online for "free", open access, and the "best" learning and training material, ideas, and processes? Do our students already independently "vote with their feet" and "their behavior", from "class attendance" (both physically, and mentally, not to mention being emotionally "present", or not being "present")? [1].

At the end of the day we come back to the individual, who is the learner, and practitioner; who is trained, undergoes a training process, which is lifelong (both professional, and personal, as a lifelong, adaptable and adaptive learner, who ideally is trained formally and informally in the science of effective and efficient learning); who is certified and licensed to practice, and both maintains and regularly renews this license to practice (through rigorous evaluation and assessment, by both a formal recognized training organizationuniversity, teaching hospital, training program; and both international and local licensing authority professional association, e.g., fellowship and local license to practice). Continuous improvement and transformation of this lengthy longitudinal professional training and certification to practice path offers several, if not many opportunities to blend the "best use" of human guided training, feedback and coaching with technology tools and platforms (including AI, VR, AR, MR, robotics, simulation paradigms, and simulators, as well as pervasive or regularly sampled indicators and data of both performance and outcomes with learning and performance analytics). We augment this with visibility, data, performance and outcome analysis and analytics of professional teams, and both localized and larger health systems and networks; in order to build a high functioning, high quality efficient and effective, safe clinical teams, and health systems, at local, regional, countrywide; and even at international levels. Why not? Blending the best of "human intelligence" and AI could potentially, can, and should allow us to scale best practices [1].

\section{ORCID:}

Poh Sun Goh: https://orcid.org/0000-0002-1531-2053

Acknowledgements: None.

Funding: No funding was obtained for this study.

Conflicts of interest: No potential conflict of interest relevant to this article was reported.

Author contributions: All work was done by Poh Sun Goh.

\section{References}

1. Goh PS. The vision of transformation in medical education after the COVID-19 pandemic. https:// medicaleducationelearning.blogspot.com/2021/04/the-visi on-of-transformation-in-medical.html. Published April 2021. Accessed June 8, 2021.

2. Prober CG, Khan S. Medical education reimagined: a call 
to action. Acad Med. 2013;88(10):1407-1410.

3. Caretta-Weyer HA, Chan T, Bigham BL, et al. If we could turn back time: imagining time-variable, competency-based medical education in the context of COVID-19. Med Teach. 2021 May 23 [Epub]. https:// doi.org/10.1080/0142159X.2021.1925641.

4. Goh PS. Medical educator roles of the future. Med Sci Educ. 2020 Sep 30 [Epub]. https://doi.org/10.1007/ s40670-020-01086-w.

5. Goh PS, Sandars J. A vision of the use of technology in medical education after the COVID-19 pandemic. https://doi.org/10.15694/mep.2020.000049.1. Published March 2020. Accessed June 8, 2021.
6. Goh PS. Technology enhanced learning in medical education: what's new, what's useful, and some important considerations. https://doi.org/10.15694/mep. 2016.000102. Published October 2016. Accessed June 8, 2021.

7. Emanuel EJ. The inevitable reimagining of medical education. JAMA. 2020;323(12):1127-1128.

8. Wartman SA, Combs CD. Reimagining medical education in the age of AI. AMA J Ethics. 2019;21(2): E146-E152.

9. Christensen CM, Hall T, Dillon K, Duncan DS. Know your customers' jobs to be done. Harv Bus Rev. 2016; 94(9):54-62. 